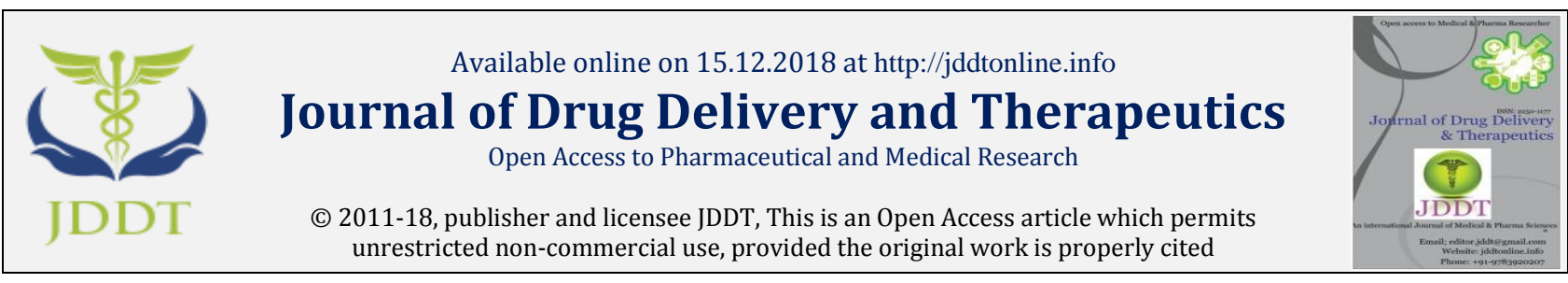

Open $\odot$ Access

Review Article

\title{
Antioxidants: a brief review
}

\author{
*Rekha Bisht \\ Indore Institute of Pharmacy, Indore (M.P.), India
}

\begin{abstract}
The field of free radical chemistry has gained a great deal of attention in recent years. Free radicals reactive oxygen species generated by our body by various endogenous systems leads to various pathological conditions. A balance between free radicals and antioxidants is prerequisite for proper physiological function. Oxidative stress caused by generation of free radicals adversely alters lipids, proteins, and DNA and provokes a number of human ailments. Oxidative stress can be managed by using external sources of antioxidants. Synthetic antioxidants such as butylated hydroxytoluene and butylated hydroxyanisole have recently been reported to be harmful for human health. Thus, the search for effective, nontoxic natural compounds with antioxidant activity has been escalated in recent years. The present review provides a brief overview on antioxidants and natural sources of antioxidants in the management of human diseases.
\end{abstract}

Keywords: free radical, Oxidative stress, antioxidants,

Article Info: Received 21 Oct, 2018; Review Completed 03 Dec 2018; Accepted 05 Dec 2018; Available online 15 Dec 2018

\section{Cite this article as:}

Bisht R, Antioxidants: a brief review, Journal of Drug Delivery and Therapeutics. 2018; 8(6-s):373-376

DOI: http://dx.doi.org/10.22270/jddt.v8i6-s.2116

*Address for Correspondence:

Dr. Rekha Bisht, Assistant Professor, Indore Institute of Pharmacy, Indore, M.P., India

\section{INTRODUCTION}

An antioxidant is a molecule that prevents the consumption of oxygen. It is capable of repressing or slowing the oxidation of other molecules. Oxidation is a chemical reaction that transfers electron from a substance to an oxidizing agent ${ }^{1}$. These chemical reactions can produce free radicals and these radicals are capable of initiating wide variety of toxic oxidative reactions such as peroxidation of membrane lipids, direct inhibition of mitochondrial respiratory chain enzymes, fragmentation or random cross linking of molecules like DNA, enzymes and proteins and can commence different degenerative diseases like neurological disorders, cancer, emphysema, cirrhosis, atherosclerosis, arthritis etc ${ }^{2,3}$.

Free radicals have an unpaired electron that causes them to seek out and capture electrons from other substances in order to neutralize themselves. Although the initial attack causes the free radical to become neutralized, another free radical is generated in the process, causing a chain reaction to initiate. And until subsequent free radicals are deactivated, thousands of free radical reactions can occur within seconds of the initial reaction. Antioxidants play an important role in deactivating the free radicals before they attack cells ${ }^{1}$.

\section{Reactive Oxygen Species}

Reactive oxygen species (ROS) are described as highly reactive, oxygen containing molecules, including free radicals. They are generated as a by-product of cellular metabolic pathways and play an important role as a critical second messenger in a variety of intracellular signaling pathways. Defect in the anti-oxidant defense system and excessive intracellular generation of ROS resulting in oxidative stress ${ }^{4}$. Different types of ROS produced in cells include the hydroxyl radical, the superoxide anion radical, hydrogen peroxide, singlet oxygen, nitric oxide radical, hypochlorite radical, and various lipid peroxides ${ }^{1,5}$. The common feature for all ROS is their capability of reacting with membrane lipids, nucleic acids, proteins and enzymes, and other small molecules, resulting in cellular damage ${ }^{1}$.

\section{Protection}

It is well documented that antioxidants terminate chain reactions by removing free radical intermediates, and inhibit other oxidation reactions. ROS formation has been reported to be a significant step leading various age related neurodegenerative disorders such as Alzheimer's disease and Parkinson's disease ${ }^{6}$. ROS including superoxide radicals, hydroxyl radicals, singlet oxygen and hydrogen peroxide are often generated as byproducts of biological reaction or from exogenous factors. However, these ROS produced by sunlight, ultraviolet light, ionizing radiation, chemical reactions and metabolic processes have various pathological effects such as DNA damage, carcinogenesis and various degenerative disorders such as cardiovascular diseases, aging and neuro-degenerative diseases ${ }^{7}$.

Naturally produced antioxidant such as ascorbic acid, vitamin $\mathrm{E}$ and phenolic compounds, posses the ability to reduce the oxidative damage associated with many diseases, including cancer, cardiovascular diseases, cataracts, atherosclerosis, diabetes, arthritis, immune deficiency disease and ageing. Antioxidant compounds may act as free radical scavengers, complexes of pro-oxidant 
metals, reducing agents and quenchers of singlet oxygen formation. Synthetic antioxidant such as butylated hydroxytoluene (BHT) and butylated hydroxyanisole (BHA) have restricted use in foods as they are suspected to be carcinogenic. Therefore, in recent years the importance of search for natural antioxidant has widely increased globally ${ }^{8}$.

Measurement of total antioxidant activity in body fluids is of important prognostic and diagnostic values in patients with atherosclerosis, reperfusion injury, septic shock and diabetes. The multiple defense system present in our body against damaging free radicals is collectively called antioxidants. These antioxidants are present in the serum and are measurable 9 .

To protect the cells and organ systems of the body against ROS, humans have evolved a highly sophisticated and complex antioxidant protection system. It involves a variety of components, both endogenous and exogenous in origin, that function interactively and synergistically to neutralize free radicals. These components include:

- Nutrient-derived antioxidants like ascorbic acid (vitamin C), tocopherols and tocotrienols (vitamin E), carotenoids, and other low molecular weight compounds such as glutathione and lipoic acid.

- Antioxidant enzymes, e.g., superoxide dismutase, glutathione peroxidase, and glutathione reductase, which catalyze free radical quenching reactions.

- Metal binding proteins, such as ferritin, lactoferrin, albumin, and ceruloplasmin that sequester free iron and copper ions that are capable of catalyzing oxidative reactions.

- Numerous other antioxidant phytonutrients present in a wide variety of plant foods ${ }^{1}$.

\section{Oxidative Stress}

Oxidative stress is defined as an imbalance between oxidants and antioxidants in favour of the oxidants, potentially leading to damage, is termed 'oxidative stress 10. Increased oxidative stress at the cellular level occurs as a consequence of many factors, including exposure to alcohol, medications, trauma, cold, infections, poor diet, toxins, radiation, or strenuous physical activity. Protection against all of these processes is dependent upon the adequacy of various antioxidant substances that are derived either directly or indirectly from the diet. Consequently, an inadequate intake of antioxidant nutrients may compromise antioxidant potential, thus compounding overall oxidative stresses ${ }^{1}$.

\section{Antioxidant Enzymes}

In addition to dietary antioxidants, protection of the body against free radicals is provided by antioxidant enzymes which come under a distinctive group, concerned solely with the detoxification of these radicals ${ }^{11}$. The antioxidant enzymes such as GPx (glutathione peroxidase), heme peroxidase, CAT (catalase), and SOD (superoxide dismutases) metabolize oxidative toxic intermediates and require micronutrient cofactors such as selenium, iron, copper, zinc, and manganese for maximum catalytic activity.

\section{Superoxide Dismutases (SOD)}

Superoxide dismutases were the first genuine ROSmetabolizing enzymes discovered ${ }^{12}$. SOD (EC 1.15.1.1) is the antioxidant enzyme that catalyzed the dismutation of the highly reactive superoxide anion to $\mathrm{O}_{2}$ and to the less reactive species $\mathrm{H}_{2} \mathrm{O}_{2}$. Peroxide can be destroyed by CAT or GPX reactions $13,14,15$. In SOD catalyzed reaction, two molecules of superoxide form hydrogen peroxide and molecular oxygen and is thereby a source of cellular hydrogen peroxide ${ }^{16}$.

$$
\mathrm{O}_{2}^{-}+\mathrm{O}_{2}^{-}+2 \mathrm{H}^{+} \stackrel{\text { SoD }}{\longrightarrow} \mathrm{H}_{2} \mathrm{O}_{2}+\mathrm{O}_{2}
$$

This enzyme has significant role in rejuvenation and repair of cells, while reducing the damages caused by free radicals. SOD is found in our skin and it is essential for our body to generate adequate amounts of skin-building cells called fibroblasts. Among the common natural sources of SOD are cabbage, Brussels sprouts, wheat grass, barley grass and broccoli. SOD plays an important role in preventing the development of the Lou Gehrig's disease, also known as Amyotrophic Lateral Sclerosis (ALS). ALS affects the nerve cells in the spinal cord and brain that can lead to death of the patient ${ }^{17}$.

\section{Superoxide Reductases (SOR)}

SOR, a novel type of superoxide scavenging enzyme discovered recently, catalyzes the direct reduction of superoxide:

$$
\mathrm{O}_{2} \cdot+\mathrm{e}_{-}+2 \mathrm{H}^{+} \longrightarrow \mathrm{H}_{2} \mathrm{O}_{2}
$$

The superoxide reductases (SOR) contain iron and found in anaerobic sulfate-reducing bacteria, here called desulfoferrodoxin, the anaerobic archaea Pyrococcus furiosus, or the microaerophilic bacterium causing venereal syphilis, Treponema pallidum. The later organism lacks SOD and seems to rely solely on SOR for its elimination of superoxide. Yet there is no evidence for a mammalian SOR ${ }^{16}$.

\section{Catalases (CAT)}

Catalase enzyme catalyzes the dismutation of hydrogen peroxide to water and molecular oxygen ${ }^{16}$.

$$
2 \mathrm{H}_{2} \mathrm{O}_{2} \longrightarrow \mathrm{O}_{2^{-}}+2 \mathrm{H}_{2} \mathrm{O}
$$

Catalase also has functions in detoxifying different substrates, e.g., phenols and alcohols, via coupled reduction of hydrogen peroxide ${ }^{16}$ :

$$
\mathrm{H}_{2} \mathrm{O}_{2}+\mathrm{R}^{\prime} \mathrm{H}_{2} \longrightarrow \mathrm{R}^{\prime}+2 \mathrm{H}_{2} \mathrm{O}
$$

CAT is used in the food industry for removing hydrogen peroxide from milk prior to cheese production, in food wrappers where it prevents food from oxidizing, in the textile industry for removing hydrogen peroxide from fabrics to make sure the material is peroxide-free. It is also used in contact lens hygiene - a few lens-cleaning products disinfect the lens using a hydrogen peroxide solution; a solution containing CAT is then used to decompose the hydrogen peroxide before the lens is used again. CAT has also begun to be used in the aesthetics industry. With the aim of increasing cellular oxygenation in the upper layers of the epidermis, several mask treatments combine the enzyme with hydrogen peroxide on the face ${ }^{17}$.

\section{Glutathione Peroxidase (GPx)}

Glutathione peroxidase (GPx) is responsible for protecting cells from damage due to free radicals like hydrogen and lipid peroxides.

$$
\mathrm{ROOH}+2 \mathrm{GSH} \longrightarrow \mathrm{ROH}+\mathrm{GSSG}+\mathrm{H} 2 \mathrm{O}
$$

There are five GPx isoenzymes found in mammals and levels of each isoform vary depending on the tissue type. Cytosolic and mitochondrial glutathione peroxidase (cGPx 
or GPx1) reduces fatty acid hydroperoxides and $\mathrm{H}_{2} \mathrm{O}_{2}$ at the expense of glutathione. GPx1 and the phospholipid hydroperoxide glutathione peroxidase (PHGPx or GPx4) are found in most tissues. GPx4 is located in both the cytosol and the membrane fraction. GPx4 can directly reduce the phospholipid hydroperoxides, fatty acid hydroperoxides, and cholesterol hydroperoxides that are produced in peroxidized membranes and oxidized lipoproteins. GPx1 is predominantly present in erythrocytes, kidney, and liver, and GPx4 is highly expressed in renal epithelial cells and testes. Cytosolic GPx2 or GPx-G1, and extracellular GPx3 or GPx-P is poorly detected in most tissues except for the gastrointestinal tract and kidney, respectively ${ }^{16,17}$.

All glutathione peroxidases may catalyze the reduction of $\mathrm{H}_{2} \mathrm{O}_{2}$ using glutathione as substrate. They can also reduce other peroxides (e.g., lipid peroxides in cell membranes) to alcohols. Levels of GPx in the body are closely linked with that of glutathione, the master antioxidant. Glutathione (GSH) protects the cells against ill effects of pollution and also acts as our body's immune system boosters ${ }^{16,17}$.

\section{Peroxiredoxins (Prx)}

Peroxiredoxins (Prx; thioredoxin peroxidases), recently discovered enzymes, directly reduces peroxides, e.g., hydrogen peroxide and different alkyl hydroperoxides. Thioredoxin (in mammalian cells), trypanothione (in trypanosomatids) or AhpF, a component of the alkyl hydroperoxide reductase system in Salmonella typhimurium, regenerate oxidized Prx formed in the catalytic cycle. In the mitochondria of mammalian cells the mitochondrial thioredoxin system is probably a specific reductant of Prx. Peroxiredoxins have been shown to inhibit apoptosis induced by p53 and by hydrogen peroxide on a level upstream of bcl-2. As of today, at least 13 mammalian peroxiredoxins are known ${ }^{15}$.

\section{Indian Medicinal Plants with Antioxidant Activity}

Synthetic antioxidants are available for processed foods such as BHT (butylated hydroxytoluene), (BHA) butylated hydroxyanisole and tertiary butyl hydroquinone but it has been suggested that these synthetic antioxidants are toxic to liver and cause mutagenesis.

Therefore there is a great propensity towards natural antioxidant sources such as plant derivatives ${ }^{3}$. Plants are excellent source of biologically active compounds known as phytochemicals and these phytochemicals have been found to act as antioxidants by scavenging free radicals, and many have therapeutic potential for free radical associated disorders ${ }^{18}$.

To prevent the oxidative stress plants produces significant amount of antioxidants. They represent a potential source of new compounds with antioxidant activity. Antioxidants have many potential applications, especially in relation to human health, both in terms of prevention of disease and therapy. Indian medicinal plants provide a rich source of antioxidants. Following are the Indian medicinal plants with antioxidant abilities at various levels of protection 19 (Table 1).

Table1: Indian Medicinal Plants and Levels of Antioxidant Action

\begin{tabular}{|l|l|}
\hline $\begin{array}{l}\text { Level 1: } \begin{array}{l}\text { Suppression of } \\
\text { radical formation }\end{array} \\
\text { Level 2: }\end{array}$ & $\begin{array}{l}\text { Momordica charantia, Murraya koenigii, Ocimum sanctum, Picrorhiza kurroa, Sida cordifolia, Spirulina } \\
\text { fusiformis, Tinospora cordifolia, Vinca rosea, Withania somnifera \& Zingiber officinale }\end{array}$ \\
$\begin{array}{l}\text { Scavenging of } \\
\text { primary radicals }\end{array}$ & $\begin{array}{l}\text { Acacia catechu, Aloe vera, Butea monosperma, Crocus sativus, Curcuma longa, Hippophae rhamnoides, } \\
\text { Indigofera tinctoria, Momordica charantia, Ocimum sanctum, Plumbago zeylanica, Psoralea corylifolia, } \\
\text { Rotula aquatica \& Swertia decussate }\end{array}$ \\
\hline $\begin{array}{l}\text { Level 3: } \\
\text { Scavenging of } \\
\text { secondary } \\
\text { radicals }\end{array}$ & $\begin{array}{l}\text { Allium sativum, Allium cepa, Aloe vera, Amaranthus blitum, Argemon maxicana, Asparagus racemosus, } \\
\text { Azadirachta indica, Curcuma longa, Emblica officinalis, Glycyrrhiza glabra, Hemidesmus indicus, } \\
\text { Mangifera indica, Momordica charantia, Murraya koenigii, Ocimum sanctum, Onosoma echioides, } \\
\text { Picrorhiza kurroa, Piper betel, Plumbago zeylanica, Psoralea corylifolia, Sesamum indicum, Sida } \\
\text { cordifolia, Swertia decussata, Terminalia bellarica, Tinospora cordifolia, Vinca rosea, Withania } \\
\text { somnifera \&Zingiber officinale }\end{array}$ \\
\hline $\begin{array}{l}\text { Level 4: } \\
\text { meconstitution of }\end{array}$ & $\begin{array}{l}\text { Allium sativum, Aloe vera, Camellia sinensis, Curcuma longa, Argemon maxicana, Cassia occidentalis, } \\
\text { Crocus sativus, Emblica officinalis, Ocimum sanctum, Tinospora cordifolia, Vinca rosea, Withania } \\
\text { somnifera \& Zingiber officinale }\end{array}$ \\
\hline $\begin{array}{l}\text { Level 5: } \\
\text { Repair of damage }\end{array}$ & Ocimum sanctum \& Hibiscus sabdariffa \\
\hline
\end{tabular}

\section{CONCLUSION}

Damage caused by the free radical generation due to oxidative stress contributes to various chronic health problems such as cardiovascular and inflammatory disease, diabetes, cataract, and cancer. Antioxidants prevent free radical induced tissue damage by inhibiting the formation of radicals, scavenging them, or by enhancing their decomposition. Synthetic antioxidants are reported to be harmful to human health. Thus the search for effective, nontoxic natural compounds with antioxidant activity has been escalated in recent years. 


\section{REFERENCES}

1. Percival M. Clinical nutrition insights. Advanced nutrition publications, Inc., Revised, 1998:1-4.

2. Meena H, Pandey HK, Pandey P, Arya MC, Ahmed Z. Evaluation of antioxidant activity of two important memory enhancing medicinal plants Baccopa monnieri and Centella asiatica. Indian Journal of Pharmacology, 2012; 44(1):114117.

3. Premathilaka R, Wickramasinghe I, Hewage S. In vitro antioxidant activity of leaf extracts in three medicinal plants; Costus specious (Koen.) Smith, Coccinia grandis (L.) J. Voigt and Wattakaka Volubilis. European Journal of Academic Essays, 2016; 3(3):141-146.

4. Bras ML, Clément MV, Pervaiz S, Brenner C. Reactive oxygen species and the mitochondrial signaling pathway of cell death. Histology and Histopathology, 2005; 20:205-220.

5. Aprioku JS. Pharmacology of Free Radicals and the Impact of Reactive Oxygen Species on the Testis. The Journal of Reproduction and Infertility, 2013; 14(4):158-172.

6. Sies H., Antioxidants in Disease, Mechanisms and Therapy. Academic Press, New York; 1996.

7. Halliwell B, Gutteridge JMC. Free Radicals in Biology and Medicine. Oxford University Press, Oxford; 1997.

8. Lu J, Zheng YL, Wu DM, Sun DX, Shan Q. Ursolic acid ameliorates cognition deficits and attenuates oxidative damage in the brain of senescent mice induced by Dgalactose. Biochemistry and Pharmacology, 2007; 74(7):1078-1090.

9. Gupta R, Sharma M, Reddy KS. Improved method of total antioxidant assay. Indian Journal of Biochemistry and Biophysics, 2009; 46:126-129.

10. Sies H. Oxidative stress: oxidants and antioxidants. Experimental Physiology, 1997; 82(2):291-5.
11. Jeeva JS, Sunitha J, Ananthalakshmi R, Rajkumari S, Ramesh M, Krishnan R. Enzymatic antioxidants and its role in oral diseases. The Journal of Pharmacy and Bioallied Sciences, 2015; 7:S331-3.

12. McCord JM, Fridovich I. Superoxide dismutase: an enzymatic function for erythrocuprein (hemocuprein). The Journal of biological chemistry, 1969; 244:6049-6055.

13. Fridovich I. Superoxide radical and superoxide dismutases. Annual Review of Biochemistry, 1995; 64:97-112.

14. Teixeira HD, Schumacher RI, Meneghini R. Lower intracellular hydrogen peroxide levels in cells overexpressing $\mathrm{Cu}-\mathrm{Zn}$ superoxide dismutase. Proceedings of the National Academy of Sciences, 1998; 95:7872-5.

15. Sandalio LM, Lo'pez-Huertas E and Bueno P. Immunocytochemical localization of copper, zinc superoxide dismutase in peroxisomes from watermelon (Citrullus vulgaris Schrad.) cotyledons. Free Radical Research, 1997; 26:187-94.

16. Nordberg J, Elias S, Arner J. Reactive oxygen species, antioxidants, and the mammalian thioredoxin system. Free Radical Biology and Medicine, 2001; 31(11):1287-1312.

17. Krishnamurthy $\mathrm{P}$, Wadhwani A, 2012. Antioxidant enzymes and human health. http://dx.doi.org/10.5772/48109 accessed on $7 / 9 / 2013$.

18. Molan AL, Faraj AM, Mahd AS. Antioxidant activity and phenolic content of some medicinal plants traditionally used in Northern Iraq. Phytopharmacology, 2012; 2(2):224-233.

19. Ali SS, Kasoju N, Luthra A, Singh A, Sharanabasava H, Sahu A, Bora U,. Indian medicinal herbs as sources of antioxidants. Food Research International, 2008; 41(1):1-15. 